\title{
Comparison between Central and Brachial Blood Pressure in Hypertensive Elderly Women and Men
}

\author{
Bruno Bordin Pelazza and Sebastião Rodrigues Ferreira Filho \\ Postgraduate Program in Health Sciences, The Federal University of Uberlândia, Uberlândia, MG, Brazil \\ Correspondence should be addressed to Sebastião Rodrigues Ferreira Filho; sebahferreira@gmail.com
}

Received 4 April 2017; Accepted 17 August 2017; Published 20 September 2017

Academic Editor: Markus P. Schlaich

Copyright ( 2017 Bruno Bordin Pelazza and Sebastião Rodrigues Ferreira Filho. This is an open access article distributed under the Creative Commons Attribution License, which permits unrestricted use, distribution, and reproduction in any medium, provided the original work is properly cited.

\begin{abstract}
Aim. To compare the values of central and brachial systemic blood pressure (SBP) between women and men over 60 years of age with systemic arterial hypertension. Methods. This study was a quantitative, descriptive, cross-sectional study with elderly patients admitted to and selected from spontaneous and scheduled demand at basic health units in Uberlândia, Minas Gerais, Brazil, between March 2013 and March 2014. We included 69 study participants and compared central and brachial SBP using a Sphygmocor ${ }^{\circledR}$ XCEL device (AtCor Medical, Sydney, Australia). Results. Significant differences were found in the blood pressure values of the whole population in the central versus brachial systolic blood pressure (SP) [140(21) versus $153(23) \mathrm{mmHg}]$ and in the central versus brachial pulse pressure (PP) [55(18) versus 70(18) $\mathrm{mmHg}]$. Additionally, females exhibited higher blood pressure levels than males [central SP 144(23) versus 134(16) mmHg and brachial SP 161(26) versus 148(18) mmHg and central PP 62(17) versus 45(14) $\mathrm{mmHg}$ and brachial PP 80(21) versus 63(15) $\mathrm{mmHg}$, resp.]. Conclusion. Elderly women exhibited higher blood pressure values than elderly hypertensive men.
\end{abstract}

\section{Introduction}

Systemic blood pressure (SBP) changes with ageing. Systolic blood pressure (SP) rises progressively, whereas diastolic blood pressure (DP) rises until the 6th decade of life and then stabilizes or gradually decreases [1-4].

SBP levels measured indirectly through cuffs placed either on the upper limbs or at the aortic root [the central SBP levels $(\mathrm{SBPC})]$ constitute independent factors for cardiovascular risk (CVR) [5, 6]. Evidence has shown that SBPc, compared with brachial SBP $(\mathrm{SBPb})$, is more closely associated with the injury of target organs [6-15]. Among the SBP components, Jankowski et al. [9] demonstrated that SP and pulse pressure (PP) were early and independent markers of CVR, whereas other studies described PP as a new marker of cardiovascular disease (CVD) [8-12]. In the elderly of both sexes, progressive arterial stiffness and early reflection waves amplify PP and elevate SP $[6,16]$. Other contributors to vascular stiffness also exist, especially in women.

Epidemiological studies have confirmed that the physiological hormonal changes that occur in women during and after menopause affect the systemic circulation, thereby increasing SBP and consequently CVR. Additionally, CVD is the leading cause of mortality in postmenopausal women, with a prevalence equal to or higher than the prevalence in men due to low plasma oestrogen levels, among other factors [17-20].

As good markers of CVR, central and peripheral blood pressure values could diverge in the same patient and behave differently in elderly female patients. Therefore, the objective of the present study is to compare the central and brachial SBP values between women and men over 60 years of age with systemic arterial hypertension (SAH).

\section{Materials and Methods}

2.1. Population and Study Design. This study was a quantitative, descriptive, cross-sectional study with elderly patients $\geq 60$ years of age who were admitted and selected from the spontaneous and scheduled demand at basic health units (BHUs) in the municipal network of Uberlândia, Minas Gerais, Brazil, from March 2013 to March 2014. The first 69 
TABLE 1: Clinical characteristics of the groups and the number of antihypertensive agents.

\begin{tabular}{|c|c|c|c|}
\hline Parameters & Overall population $(n=69)$ & Women $(n=39)$ & $\operatorname{Men}(n=30)$ \\
\hline Age & $70(7)$ & $71(7)$ & $68(7)$ \\
\hline Sedentary lifestyle (\%) & 62 & 62 & 63 \\
\hline Smoking (\%) & 14 & 10 & 20 \\
\hline Diabetes (\%) & 35 & 33 & 37 \\
\hline Weight (kg) & $79(17)$ & $76(17)$ & $83(16)$ \\
\hline Height $(\mathrm{cm})$ & $1.6(0.1)$ & $1.5(0.1)^{*}$ & $1.7(0.1)^{*}$ \\
\hline $\mathrm{WC}(\mathrm{cm})$ & $102(16)$ & $102(15)$ & $103(17)$ \\
\hline BMI & $31(6)$ & $32(8)$ & $30(5)$ \\
\hline Antihypertensive drugs $(n)$ & $1.6(1.3)$ & $1.8(1.3)$ & $1.4(1.3)$ \\
\hline $\mathrm{BB}(\%)$ & 33 & 38 & 27 \\
\hline CCB $(\%)$ & 13 & 10 & 17 \\
\hline $\mathrm{ARB}(\%)$ & 35 & 36 & 33 \\
\hline Vasodilator (\%) & 3 & 3 & 3 \\
\hline $\operatorname{ACEI}(\%)$ & 30 & 31 & 30 \\
\hline Diuretics (\%) & 41 & $49^{*}$ & $30^{*}$ \\
\hline Controlled hypertensives (\%) & 41 & 41 & 40 \\
\hline
\end{tabular}

$*=$ comparison between women and men $(P<0.05) ;()=$ standard deviation; WC $=$ waist circumference; $\mathrm{BMI}=$ body mass index; $n=$ number; $\%=$ percentage; $\mathrm{kg}=$ kilogram; $\mathrm{cm}=$ centimetres; $\mathrm{BB}=$ beta-adrenergic blocker; $\mathrm{CCB}=$ calcium channel blocker; $\mathrm{ARB}=$ angiotensin receptor blocker; $\mathrm{ACEI}=$ angiotensin-converting enzyme inhibitor.

hypertensive participants were included in the study and were divided into three groups of patients as follows: (I) overall study population: $70 \pm 7.3$ years, $n=69$; (II) women: $71 \pm 7$ years, $n=39$; and (III) men: $68 \pm 6.5$ years, $n=30$. All patients were active, stable, and conscious.

This study was conducted in accordance with the attributes defined in Resolution CNS 466/12 and approved by the Ethics Committee in Research of the Federal University of Uberlândia under opinion number 224,540 and CAAE 37440114.3.0000.5152.

2.2. SBP Measurement. Patients with $\mathrm{SAH}, \mathrm{a} \mathrm{SBPb} \geq 140$ / $90 \mathrm{mmHg}$, or a SBPb $\leq 140 / 90 \mathrm{mmHg}$ with the use of one or more antihypertensive drugs (controlled) were considered.

A Sphygmocor XCEL applanation tonometry device (AtCor Medical, Sydney, Australia) was used to measure both SBPb and SBPc simultaneously and noninvasively. The components of the SBP surveyed were the SP, DP, PP, and mean arterial pressure (MAP) (both central and brachial). All values are expressed in $\mathrm{mmHg}$. The SBPc and SBPb measurement procedure was performed only once and was based on a previous description [21].

2.3. Statistical Analysis. The results for the continuous variables shown in Tables 1 and 2 and Figure 1 are expressed as the mean \pm standard deviation or as a proportion or percentage. First, we used BioEstat 3.0 to perform the D'Agostino-Pearson normality test. Subsequently, Student's $t$-test was applied to compare the values of the $\mathrm{SBPc}$ and $\mathrm{SBPb}$ components according to the normality of the sample. Differences were considered significant when $P<0.05$. Statistical analysis was performed using Statistical Package for Social Science (SPSS) version 20 for Windows.

\section{Results}

The clinical characteristics of the overall study population and the population according to sex are shown in Table 1. Table 1 also showed that women used significantly more diuretics than did men.

Table 2 shows the hemodynamic variables of the overall population and the respective comparisons between the women and men.

Figure 1 shows the SP and PP variables (both central and brachial) between the women and men.

\section{Discussion}

Cross-sectional and longitudinal studies have confirmed a higher prevalence of hypertension in elderly postmenopausal women $[17-19,22]$ and greater arterial stiffening compared to that in men $[20,23]$. Additionally, Piskorz and Brzostek [24] reported that postmenopausal women, compared with premenopausal women, had higher CVR and mortality [25]. One explanation for this finding is the possible decrease in the plasma oestrogen concentration, which exerts a protective effect against atherogenesis, atherosclerotic plaque formation, and, consequently, clinical manifestations of CVD [1720].

In the present study, all patients were randomly included. We observed that women presented high SPc and PPc mean values, whereas men remained within the limits considered normal $[5,26]$. We observed that the $\mathrm{SPb}$ and $\mathrm{PPb}$ values were increased in both sexes but were still higher in women (Table 2 and Figure 1).

Both SP and PP increase with age, mainly due to the decrease in elasticity of the large vessels as a consequence 
TABLE 2: Characteristics of the hemodynamic parameters of the groups.

\begin{tabular}{|c|c|c|c|}
\hline Parameters & Overall population $(n=69)$ & Women $(n=39)$ & $\operatorname{Men}(n=30)$ \\
\hline HR (bpm) & $74(19)$ & $74(20)$ & $73(19)$ \\
\hline RR (bpm) & $17(3)$ & $17(4)$ & $17(3)$ \\
\hline $\mathrm{SPc}$ versus $\mathrm{SPb}(\mathrm{mmHg})$ & $140(21) / 153(23)^{\dagger}$ & - & - \\
\hline $\mathrm{DPc}$ versus $\mathrm{DPb}(\mathrm{mmHg})$ & $84(15) / 83(15)$ & - & - \\
\hline $\mathrm{PPc}$ versus $\mathrm{PPb}(\mathrm{mmHg})$ & $55(18) / 70(18)^{\dagger}$ & - & - \\
\hline MAPc versus $\mathrm{MAPb}(\mathrm{mmHg})$ & $103(15) / 106(16)$ & - & - \\
\hline $\mathrm{SPc}(\mathrm{mmHg})$ & - & $144(23)^{*}$ & $134(16)^{*}$ \\
\hline $\mathrm{DPc}(\mathrm{mmHg})$ & - & $82(15)$ & $88(15)$ \\
\hline $\mathrm{PPc}(\mathrm{mmHg})$ & - & $62(17)^{*}$ & $45(14)^{*}$ \\
\hline MAPc $(\mathrm{mmHg})$ & - & $103(16)$ & $103(14)$ \\
\hline $\mathrm{SPb}(\mathrm{mmHg})$ & - & $161(26)^{*}$ & $148(18)^{*}$ \\
\hline $\mathrm{DPb}(\mathrm{mmHg})$ & - & $81(15)$ & $86(15)$ \\
\hline $\mathrm{PPb}(\mathrm{mmHg})$ & - & $80(21)^{*}$ & $63(15)^{*}$ \\
\hline $\mathrm{MAPb}(\mathrm{mmHg})$ & - & $106(17)$ & $107(14)$ \\
\hline AIx@75 (\%) & - & $41(12)^{*}$ & $30(8)^{*}$ \\
\hline
\end{tabular}

${ }^{\dagger}$ Comparison between the parameters of the entire population $(P<0.05) ;{ }^{*}$ comparison between parameters of the women and men $(P<0.05)$; $\%=$ percentage; ()$=$ standard deviation; $H R=$ heart rate; $R R=$ respiratory rate; $c=$ central; $b=$ brachial; $b p m=$ beats per minute; bpm $=$ breaths per minute; $\mathrm{mmHg}=$ millimetres of mercury; $\mathrm{SP}=$ systolic blood pressure; $\mathrm{DP}=$ diastolic blood pressure; $\mathrm{PP}$ = pulse pressure; $\mathrm{MAP}=$ mean arterial pressure; and AIx@75 $=$ heart rate-corrected augmentation index.

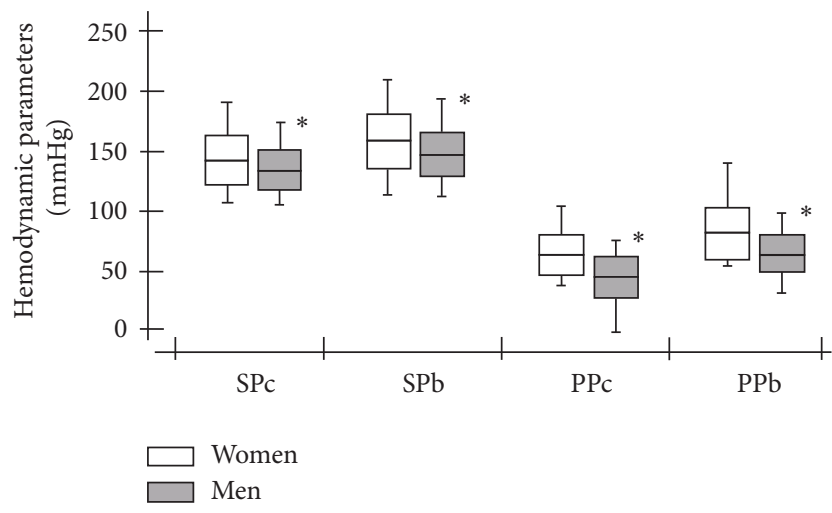

FIGURE 1: Comparison of systolic blood pressure and pulse pressure (both central and brachial) between the women and men. SPc $=$ central systolic blood pressure; $\mathrm{SPb}=$ brachial systolic blood pressure; $\mathrm{PPc}=$ central pulse pressure; $\mathrm{PPb}=$ brachial pulse pressure. ${ }^{*}$ Comparison of blood pressure parameters between all of the women and men $(P<0.05)$.

of their respective structural modifications $[1,3,4,20]$. We found that neither the central nor brachial MAP values were significant in either sex $(P<0.05)$.

Son et al. [19] conducted a study with 95 female patients with a mean age of 52 years and found that indirectly measured $\mathrm{SBPb}$ was significantly higher in postmenopausal period than in premenopausal women; additionally, the number of SAH cases increased with advancing age. In our study, the components of both central and brachial SBP were compared. We found that the SP and PP levels in the women were higher than those in the men. The hypertensive postmenopausal women in the study by Son et al. were younger than the women in the present study; thus, our data indicate that the observed difference in blood pressure levels between men and women may persist at more advanced ages than observed by other authors.

Kim et al. [27] also showed that older women had higher $\mathrm{PPb}$ values compared to premenopausal levels, but the authors did not measure the central pressures or compare the values with men. Other studies $[8,12]$ have confirmed that women and men over 60 years of age with $\mathrm{PPc} \geq 50 \mathrm{mmHg}$ exhibit an increase in cardiovascular risk/events. Because the mean PPc value in women was $62 \mathrm{mmHg}$ compared to $45 \mathrm{mmHg}$ in males, women were assumed to have a higher CVR than men in similar age groups. We observed that the brachial SP and PP were higher than the central values in the overall study population. This finding may be attributed to arterial stiffening and the premature return of the reflected wave in systole (Table 2 and Figure 1) [9, 28, 29].

The AIx@75 (heart rate-corrected augmentation index) is considered as a composite marker of reflection waves and arterial stiffness. In this sense, it was evidenced that postmenopausal women had higher arterial stiffness when compared to elderly hypertensive men (Figure 2) [30].

To the best of our knowledge, Brazilian studies demonstrating and comparing the components of central and brachial SBP in postmenopausal women with elderly hypertensive men via applanation tonometry are rare. Notably, this study is a preliminary study with the inclusion of the first 69 hypertensive patients, which will help guide future research.

\section{Limitations of the Study}

This study is a cross-sectional study with the inherent limitations of this type of design. The study patients used several classes of antihypertensive drugs, including beta-adrenergic blockers (prescribed to $33 \%$ of the overall population), which 


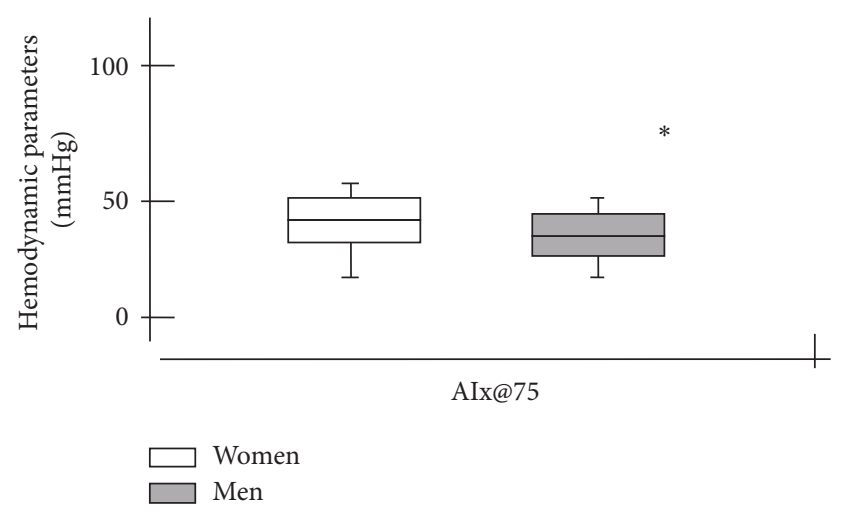

FIGURE 2: Comparison of heart rate-corrected augmentation indices between women and men. AIx@75 = heart rate-corrected augmentation index. ${ }^{*}$ Comparison of blood pressure parameters between women and men $(P<0.05)$.

do not effectively reduce central pressure levels [11-13, 31]. Additionally, the differences in the central and brachial SBP values found may be specific to the first 69 hypertensive patients analysed. Moreover, some patients examined may have exhibited acute SBP elevations due to stress during SBP measurement.

\section{Conclusion}

Significant differences were found in both the central and brachial SP and PP values between women and men. The elderly women presented higher blood pressure values than those of the elderly hypertensive men.

\section{Disclosure}

The present study is part of a doctoral thesis in the Postgraduate Program in Health Sciences of the Federal University of Uberlândia.

\section{Conflicts of Interest}

The authors declare that there are no conflicts of interest regarding the publication of this paper.

\section{Acknowledgments}

This study is funded by Research Support Foundation of Minas Gerais (Fundação de Amparo à Pesquisa do Estado de Minas Gerais (FAPEMIG)).

\section{References}

[1] J.-G. Wang, J. A. Staessen, S. S. Franklin, R. Fagard, and F. Gueyffier, "Systolic and diastolic blood pressure lowering as determinants of cardiovascular outcome," Hypertension, vol. 45, no. 5, pp. 907-913, 2005.

[2] I. J. Brwon, I. Tzoulaki, V. Candeias, and P. Elliot, "Salt intakes around the world: implications for public health," International Journal of Epidemiology, vol. 38, pp. 791-813, 2009.
[3] B. B. Pelazza, C. A. S. Rosa, and S. R. F. Filho, "Comparação entre os valores da pressão arterial central e braquial de pacientes com hipertensão arterial submetidos à cineangiocoronariografia," Jornal Brasileiro de Nefrologia, vol. 34, no. 3, pp. 266-271, 2012.

[4] B. B. Pelazza and S. R. F. Filho, "Comparação entre os valores da Pressão de Pulso em Hipertensos Controlados e não Controlados," Revista Brasileira de Cardiologia, vol. 26, no. 6, pp. 472480, 2013.

[5] V. L. Roger, A. S. Go, D. M. Lloyd-Jones et al., "Heart disease and stroke statistics-2011 update: a report from the American Heart Association," Circulation, vol. 123, no. 4, pp. el29-e153, 2011.

[6] O. Narayan, J. Casan, M. Szarski, A. M. Dart, I. T. Meredith, and J. D. Cameron, "Estimation of central aortic blood pressure: A systematic meta-analysis of available techniques," Journal of Hypertension, vol. 32, no. 9, pp. 1727-1740, 2014.

[7] J. E. Sharman, T. H. Marwick, D. Gilroy, P. Otahal, W. P. Abhayaratna, and M. Stowasser, "Randomized trial of guiding hypertension management using central aortic blood pressure compared with best-practice care principal findings of the BP GUIDE study," Hypertension, vol. 62, no. 6, pp. 1138-1145, 2013.

[8] M. J. Roman, R. B. Devereux, J. R. Kizer et al., "High central pulse pressure is independently associated with adverse cardiovascular outcome the strong heart study," Journal of the American College of Cardiology, vol. 54, no. 18, pp. 1730-1734, 2009.

[9] P. Jankowski, K. Kawecka-Jaszcz, D. Czarnecka et al., "Pulsatile but not steady component of blood pressure predicts cardiovascular events in coronary patients," Hypertension, vol. 51, no. 4, pp. 848-855, 2008.

[10] J. Hashimoto and S. Ito, "Central blood pressure and prediction of cardiovascular events," Current Hypertension Reviews, vol. 8, no. 2, pp. 108-113, 2012.

[11] J. Hashimoto, "Central hemodynamics and target organ damage in hypertension," Tohoku Journal of Experimental Medicine, vol. 233, no. 1, pp. 1-8, 2014.

[12] C. M. McEniery, J. R. Cockcroft, M. J. Roman, S. S. Franklin, and I. B. Wilkinson, "Central blood pressure: current evidence and clinical importance," European Heart Journal, vol. 35, no. 26, pp. 1719-1725, 2014.

[13] E. Agabiti-Rosei, G. Mancia, M. F. O’Rourke et al., "Central blood pressure measurements and antihypertensive therapy: a consensus document," Hypertension, vol. 50, no. 1, pp. 154-160, 2007.

[14] A. Avolio, "Central aortic blood pressure and management of hypertension confirmation of a paradigm shift?" Hypertension, vol. 62 , no. 6, pp. 1005-1007, 2013.

[15] F. Baschiera, W. Chang, and P. Brunel, "Effects of aliskiren- and ramipril-based treatment on central aortic blood pressure in elderly with systolic hypertension: A substudy of AGELESS," Vascular Health and Risk Management, vol. 10, pp. 389-397, 2014.

[16] I. B. Wilkinson, S. S. Franklin, I. R. Hall, S. Tyrrell, and J. R. Cockcroft, "Pressure amplification explains why pulse pressure is unrelated to risk in young subjects," Hypertension, vol. 38, no. 6, pp. 1461-1466, 2001.

[17] N. Agrinier, M. Cournot, J. Dallongeville et al., "Menopause and modifiable coronary heart disease risk factors: A population based study," Maturitas, vol. 65, no. 3, pp. 237-243, 2010.

[18] N. Akazawa, S.-G. Ra, J. Sugawara, and S. Maeda, "Influence of aerobic exercise training on post-exercise responses of aortic pulse pressure and augmentation pressure in postmenopausal women," Frontiers in Physiology, vol. 6, article no. 268, 2015. 
[19] M. K. Son, N.-K. Lim, J.-Y. Lim et al., "Difference in blood pressure between early and late menopausal transition was significant in healthy Korean women," BMC Women's Health, vol. 15, no. 1, article no. 64, 2015.

[20] G. Kolovou, V. Giannakopoulou, Y. Vasiliadis, and H. Bilianou, "Effects of estrogens on atherogenesis," Current Vascular Pharmacology, vol. 9, no. 2, pp. 244-257, 2011.

[21] D. F. Souza, A. C. Brunelli, C. I. Peres et al., "Agreement among sequential carotid-femoral pulse wave velocity (cfPWV) measurements in elderly hypertensive patients," Journal of the American Society of Hypertension, vol. 10, no. 4, pp. e36e37, 2016.

[22] B. A. Borlaug, M. M. Redfield, V. Melenovsky et al., "Longitudinal changes in left ventricular stiffness a community-based study," Circulation: Heart Failure, vol. 6, no. 5, pp. 944-952, 2013.

[23] T. K. Waddell, A. M. Dart, C. D. Gatzka, J. D. Cameron, and B. A. Kingwell, "Women exhibit a greater age-related increase in proximal aortic stiffness than men," Journal of Hypertension, vol. 19, no. 12, pp. 2205-2212, 2001.

[24] A. Piskorz and T. Brzostek, "Comparison of SCORE-predicted risk of death due to cardiovascular events in women before and after menopause," Przeglad Menopauzalny, vol. 14, no. 3, pp. 168-172, 2015.

[25] V. J. Ama Moor, J. R. Nansseu, M. E. Nouaga et al., "Assessment of the 10-year risk of cardiovascular events among a group of sub-Saharan African post-menopausal women," Cardiology Journal, vol. 23, no. 2, pp. 123-131, 2016.

[26] "Sociedade Brasileira de Cardiologia, VII Diretriz Brasileira de Hipertensão Arterial," Arquivos Brasileiros de Cardiologia, vol. 107, no. 3, pp. 1-65, 2016.

[27] S.-Y. Kim, S.-J. Joo, M.-S. Shin et al., "Clinic and home blood pressure lowering effect of an angiotensin receptor blocker, fimasartan, in postmenopausal women with hypertension," Medicine (United States), vol. 95, no. 22, Article ID e3764, 2016.

[28] A. A. Torjesen, N. Wang, M. G. Larson et al., "Forward and backward wave morphology and central pressure augmentation in men and women in the framingham heart study," Hypertension, vol. 64, no. 2, pp. 259-265, 2014.

[29] R. R. Townsend, H. R. Black, J. A. Chirinos et al., "Clinical Use of Pulse Wave Analysis: Proceedings From a Symposium Sponsored by North American Artery," Journal of Clinical Hypertension, vol. 17, no. 7, pp. 503-513, 2015.

[30] I. Durmus, Z. Kazaz, G. Altun, and A. Cansu, "Augmentation index and aortic pulse wave velocity in patients with abdominal aortic aneurysms," International Journal of Clinical and Experimental Medicine, vol. 7, no. 2, pp. 421-425, 2014.

[31] C. H. Manisty and A. D. Hughes, "Meta-analysis of the comparative effects of different classes of antihypertensive agents on brachial and central systolic blood pressure, and augmentation index," British Journal of Clinical Pharmacology, vol. 75, no. 1, pp. 79-92, 2013. 


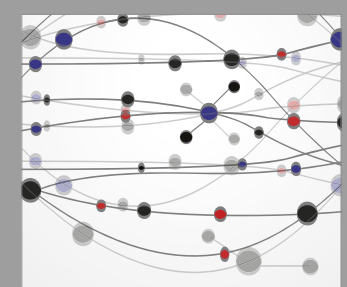

The Scientific World Journal
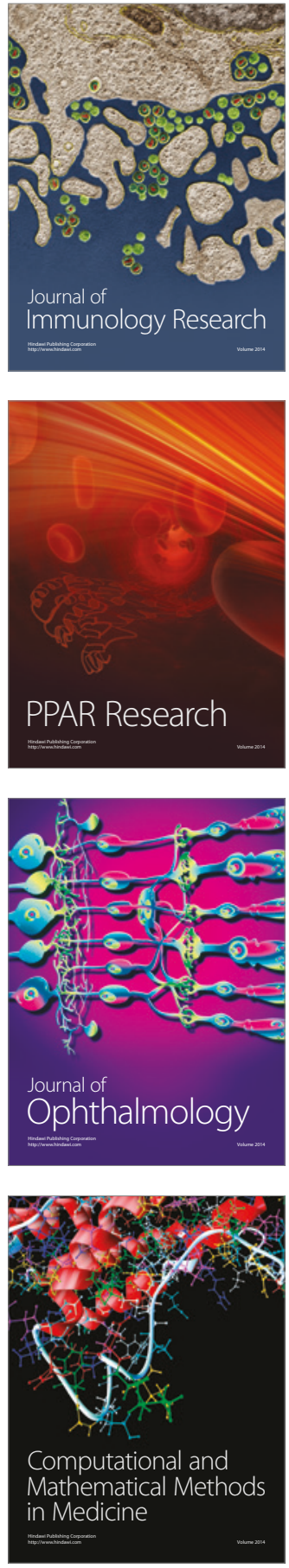

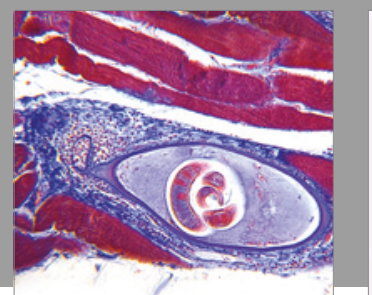

Gastroenterology Research and Practice
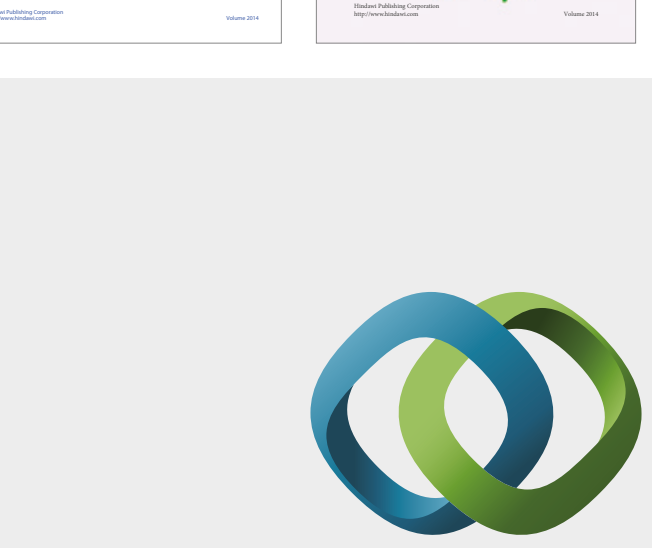

\section{Hindawi}

Submit your manuscripts at

https://www.hindawi.com
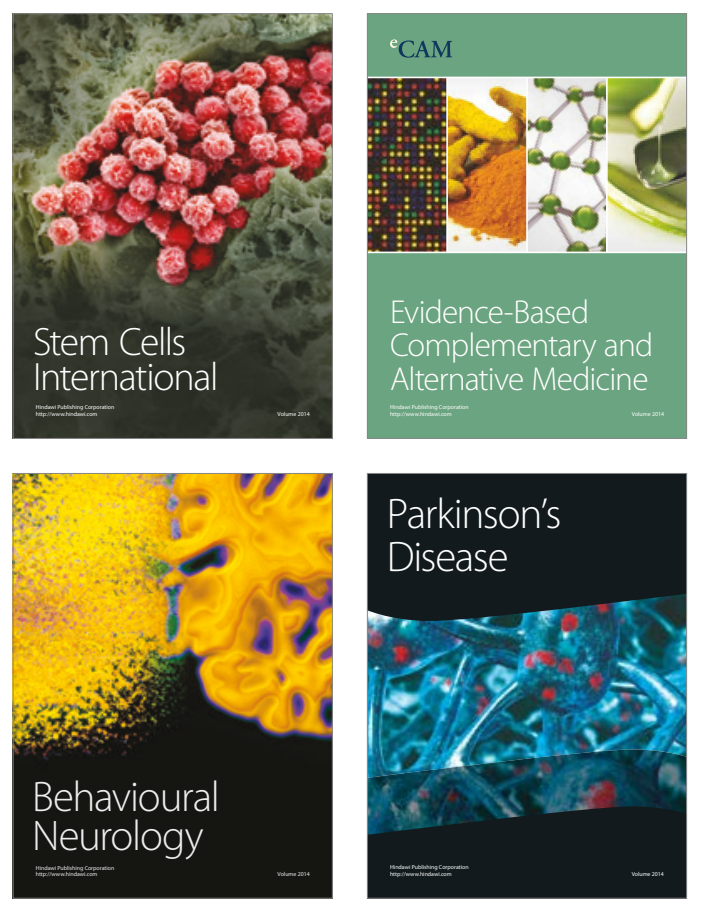
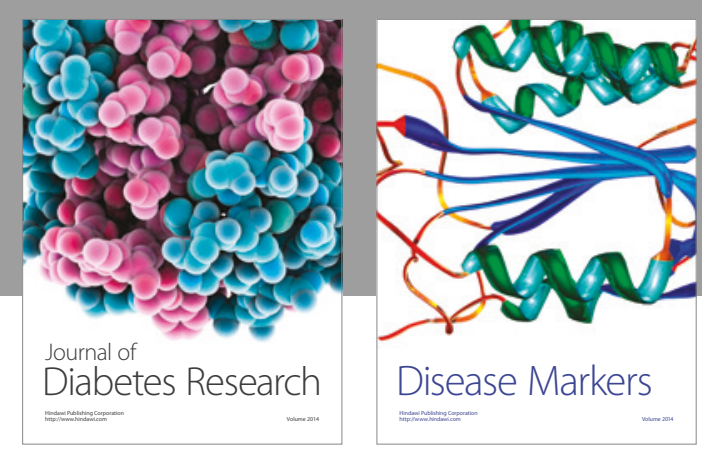

Disease Markers
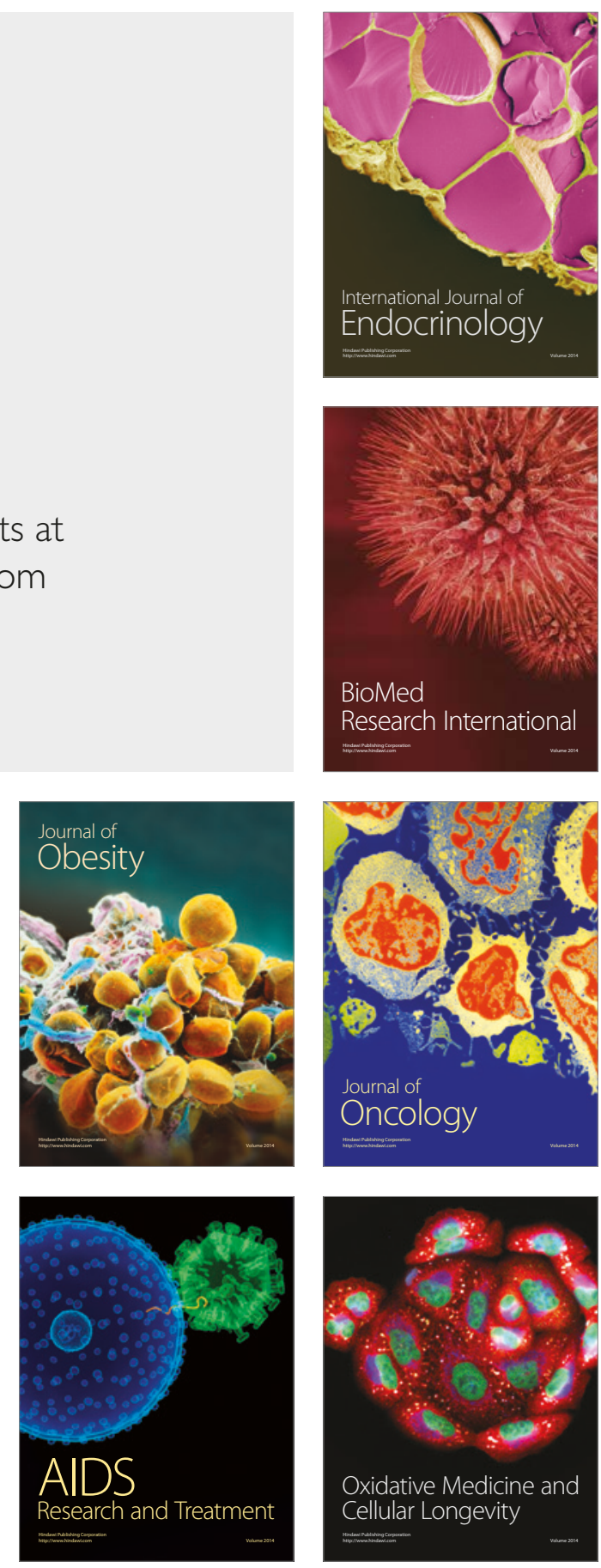